\title{
Marketing e cooperativismo: uma revisão sistemática da literatura
}

\author{
Juliana Karem Fonseca Coutinho ${ }^{1}$ \\ Janaina Gularte Cardoso ${ }^{2}$
}

\begin{abstract}
Resumo
A gestão das atividades e ferramentas de marketing contribui para que as empresas possam compreender e atender aos seus consumidores, bem como acompanhar os diversos fatores internos e externos que afetam sua atuação. No cooperativismo, o suporte do marketing apresenta-se igualmente relevante, fazendo-se necessária a aplicação de métodos flexíveis às especificidades destas instituições. Tendo em vista estes aspectos e considerando a importância das cooperativas para as regiões em que se inserem, esta pesquisa propõe uma revisão sistemática, em revistas que mantenham relação com a administração ou questões regionais e de desenvolvimento, e que apresentem classificação A2, B1 ou B2 no SICAPES. A seleção de artigos restringiu-se ao período de 1995 a 2015, com vistas a identificar o perfil e a evolução das pesquisas sobre o tema marketing em cooperativas, considerando as atividades de sistema de informação de marketing, pesquisa de marketing, planejamento de marketing e composto ou mix de marketing. Ressalta-se uma relativa carência de estudos que abordem o papel estratégico do marketing em cooperativas, embora se espere uma gradual expansão no interesse pelo assunto nos próximos anos.
\end{abstract}

Palavras-chave: Marketing. Revisão sistemática. Cooperativismo.

\section{Marketing and cooperativism: a systematic review of the literature}

\begin{abstract}
The management of activities and marketing tools helps organizations to understand and meet their consumers, and to monitor various internal and external factors affecting its performance. In the cooperativism, support marketing presents is also relevant, making needs the application of flexible methods to the specific characteristics of these institutions. Considering these aspects and considering the importance of cooperatives in the regions in which they operate, this research proposes a systematic review, in magazines classification A2, B1 and B2 in SICAPES, to maintain relationship with the administration and regional and development issues. The selection of articles was limited to the period 1995-2015, in order to identify the profile and evolution of research on the marketing theme in cooperatives, considering the marketing information system, marketing research, marketing planning and composition or marketing mix. It should be noted a relative lack of studies that address the strategic role of marketing cooperatives, although we expect a growth in interest in the subject in later years.
\end{abstract}

Keywords: Marketing. Systematic review. Cooperativism.

\footnotetext{
${ }^{1}$ Administração pela Universidade Federal da Fronteira Sul. Chapecó, SC, Brasil. juliana_kfc@ hotmail.com 2 Mestre em Administração pela Universidade Federal de Santa Catarina. Docente e Coordenadora do curso de graduação em Administração da Universidade Federal da Fronteira Sul. Chapecó, SC, Brasil. janaina.cardoso@uffs.edu.br
} 


\section{INTRODUÇÃO}

Pode-se descrever o marketing sob duas perspectivas, a social e a gerencial. Na primeira, ele é considerado um processo social de criação, oferta e livre troca de valor entre grupos e indivíduos. Na segunda, é visto muitas vezes como "a arte de vender produtos". Entretanto, a venda não é considerada a função mais importante do marketing; para Peter Drucker (1973 apud KOTLER; KELLER, 2006), o objetivo do marketing é tornar supérfluo o esforço de venda, por meio do conhecimento e compreensão acerca do cliente de modo que o produto ou serviço se adeque as suas necessidade e desejos e se venda sozinho.

Deste modo, o marketing torna-se fundamental para organizações que buscam alcançar seu público-alvo e satisfazê-lo, mantendo os atuais clientes ao mesmo tempo em que atraem novos, oferecendo-lhes um valor superior. Tendo como maior preocupação o cliente final e os stakeholders, os componentes do marketing atuam de maneira interligada, agregando valor entre si e tornando imprescindível a compreensão de todas as suas partes (SAMPAIO; DIAS, 2008).

Neste sentido, Kotler e Keller (2006) esclarecem que o marketing busca proporcionar a tomada de ações que provoquem a reação desejada em um público-alvo. Tem como um de seus objetivos identificar e satisfazer as necessidades humanas, de maneira lucrativa. Segundo McDaniel e Gates (2006, p. 6), os gerentes de marketing visam estimular a troca por meio do princípio do certo, ou seja, "tentam oferecer os bens ou serviços certos para as pessoas certas, no lugar certo, na hora certa e ao preço certo, usando as técnicas de promoção certas".

Diante dos desafios do mercado atual, exigem-se práticas novas do marketing e dos negócios. Assim, os profissionais do século XXI notam cada vez mais a necessidade de aderir a abordagens que transcendam as aplicações tradicionais do marketing, de maneira mais completa e coesa (KOTLER; KELLER, 2006).

Neste sentido Kotler e Keller (2006) sugerem a perspectiva denominada de marketing holístico, sendo uma abordagem integrada e abrangente, a fim de reconhecer e harmonizar os objetivos e as complexidades das tarefas do marketing, contemplando aspectos do marketing de relacionamento, marketing integrado, marketing interno e marketing socialmente responsável (KOTLER; KELLER, 2006).

Neste cenário, as organizações cooperativas carecem do emprego de ferramentas de marketing que contribuam para o alcance de suas metas, e que tornem possível a aplicação de modelos flexíveis às suas características e especificidades (SOUZA, 1993). As cooperativas 
são definidas por Schmidt e Perius (2003, p. 63) como "associações autônomas de pessoas que se unem voluntariamente e constituem uma empresa, de propriedade comum, para satisfazer aspirações econômicas, sociais e culturais".

Machado Filho, Marino e Conejero (2004) acreditam que o sistema cooperativista enfrenta o grande desafio de sobreviver em um ambiente competitivo ao mesmo tempo em que busca manter-se fiel aos seus princípios doutrinários. De acordo com os autores, há uma necessidade clara de aprimoramento na qualidade gerencial das cooperativas, sendo necessária a contratação de bons profissionais, bem como a adaptação de modelos de gestão às características da doutrina e da realidade cooperativista.

Considerando-se tais variáveis, este estudo propõe uma revisão sistemática da literatura tendo como base a seguinte questão de pesquisa: qual o perfil das pesquisas e a evolução do estudo do tema Marketing em Cooperativas, sob o ponto de vista das atividades referentes a sistema de informação de marketing, pesquisa de marketing, planejamento de marketing e composto ou mix de marketing, em artigos publicados em revistas com classificação A2 a B2 no SICAPES, no período de 1995 a 2015? Portanto, a presente pesquisa teve o objetivo de investigar o perfil das pesquisas e a evolução do estudo do tema Marketing em Cooperativas, sob o ponto de vista das atividades referentes a sistema de informação de marketing, pesquisa de marketing, planejamento de marketing e composto ou mix de marketing.

A revisão sistemática da literatura emprega métodos sistemáticos e explícitos para identificar, selecionar e avaliar, de forma crítica, pesquisas importantes, bem como selecionar e analisar os dados dos estudos compreendidos na revisão. Através deste tipo de pesquisa, podem-se integrar informações provenientes de estudos separados sobre um mesmo assunto, evidenciando temas e oportunizando orientação para futuras pesquisas. A revisão sistemática possibilita uma visão mais abrangente, ultrapassando conclusões obtidas com a leitura de alguns artigos (CLARKE, 2001 apud MEDEIROS et al., 2011).

Em seguida a esta introdução, este artigo contém a fundamentação teórica em seu segundo capítulo. O terceiro capítulo compreende a metodologia empregada para o alcance dos resultados. O tópico seguinte contém os resultados advindos da revisão sistemática da literatura. Por fim, expõem-se as considerações finais deste estudo.

\section{FUNDAMENTAÇÃO TEÓRICA}


O presente tópico compreende uma breve explanação acerca dos conceitos referentes ao marketing, em especial quanto às atividades de sistema de informação de marketing, pesquisa de marketing, planejamento de marketing e composto ou mix de marketing, além de explanações sobre o cooperativismo e o marketing nestas organizações.

\subsection{O MARKETING}

O marketing busca proporcionar uma tomada de ações que provoquem a reação desejada em determinado público-alvo, tendo como um de seus objetivos identificar e satisfazer as necessidades humanas (KOTLER; KELLER, 2006). A compreensão acerca do conceito de marketing tem se modificado ao longo dos anos, resultando em múltiplos conceitos ou formas de definir o marketing. O Quadro 1, a seguir, demonstra uma síntese da evolução destas definições.

Quadro 1 - Sinopse da evolução das definições de marketing

\begin{tabular}{|c|c|c|}
\hline Autor & Ano & Definição de marketing \\
\hline $\begin{array}{l}\text { 1. American Marketing } \\
\text { Association }\end{array}$ & 1960 & $\begin{array}{l}\text { "O desempenho das atividades de negócios que dirigem o fluxo de bens } \\
\text { e serviços do produtor ao consumidor ou utilizador." }\end{array}$ \\
\hline 2. Ohio State University & 1965 & $\begin{array}{l}\text { "O processo na sociedade pelo qual a estrutura da demanda para bens } \\
\text { econômicos e serviços é antecipada ou abrangida e satisfeita através da } \\
\text { concepção, promoção, troca e distribuição física de bens e serviços." }\end{array}$ \\
\hline 3. Kotler e Sidney Levy & 1969 & $\begin{array}{l}\text { "O conceito de marketing deveria abranger também as instituições não } \\
\text { lucrativas." }\end{array}$ \\
\hline 4. William Lazer & 1969 & $\begin{array}{l}\text { "O marketing deveria reconhecer as dimensões societais, isto é, levar em } \\
\text { conta as mudanças verificadas nas relações sociais." }\end{array}$ \\
\hline 5. David Luck & 1969 & $\begin{array}{l}\text { "O marketing deve limitar-se às atividades que resultem em transações } \\
\text { de mercado." }\end{array}$ \\
\hline 6. Kotler e Gerald Zaltman & 1969 & $\begin{array}{l}\text { "A criação, implementação e controle de programas calculados para } \\
\text { influenciar a aceitabilidade das ideias sociais e envolvendo } \\
\text { considerações de planejamento de produto, preço, comunicação, } \\
\text { distribuição e pesquisa de marketing." }\end{array}$ \\
\hline 7. Robert Bartls & 1974 & $\begin{array}{l}\text { "Se o marketing é para ser olhado como abrangendo as atividades } \\
\text { econômicas e não econômicas, talvez o marketing como foi } \\
\text { originalmente concebido reapareça em breve com outro nome." }\end{array}$ \\
\hline 8. Robert Hass & 1978 & $\begin{array}{l}\text { "É o processo de descoberta e interpretação das necessidades e desejos } \\
\text { do consumidor para as especificações de produto e serviço, criar a } \\
\text { demanda para esses produtos e serviços, e continuar a expandir essa } \\
\text { demanda." }\end{array}$ \\
\hline 9. Robert Hass & 1978 & $\begin{array}{l}\text { MARKETING INDUSTRIAL - "É o processo de descoberta e } \\
\text { interpretação das necessidades, desejos e expectativas do consumidor } \\
\text { industrial e das exigências para as especificações do produto e serviço e } \\
\text { continuar através de efetiva promoção, distribuição, assistência pós- } \\
\text { venda a convencer mais e mais clientes a usarem e a continuarem usando } \\
\text { esses produtos e serviços." }\end{array}$ \\
\hline 10. Philip Kotler & 1997 & $\begin{array}{l}\text { "É o processo de planejamento e execução desde a concepção, preço, } \\
\text { promoção e distribuição de ideias, bens e serviços para criar trocas que } \\
\text { satisfaçam os objetivos de pessoas e de organizações." }\end{array}$ \\
\hline
\end{tabular}

Fonte: Cobra (2011, p. 27) 
Destaca-se ainda a definição apresentada pela American Marketing Association (2013) segundo a qual o marketing "O Marketing é uma atividade, conjunto de instituições e processos para criar, comunicar, entregar e trocar ofertas que tenham valor para os consumidores, clientes, parceiros e sociedade em geral”.

Las Casas (2012) considera que o administrador de marketing obtém informações do ambiente e, a partir destas informações, adapta o composto de marketing, para satisfazer os desejos e necessidades dos clientes visados. De modo sucinto, as funções administrativas são: estabelecer objetivos organizacionais, o mercado selecionado e verificar as condições para atendê-lo, desenvolver o composto de marketing, além de verificar o alcance dos objetivos.

No mesmo sentido, Ferrell e Hartline (2005) consideram como principais atividades do marketing o planejamento tático e estratégico, desenvolvimento de planos de marketing, realização de pesquisas e análises (análise interna, competitiva, ambiental e sobre consumidores), além de desenvolver metas e objetivos.

Em seguida, abordam-se os conceitos referentes a algumas das principais atividades de marketing, a saber, o sistema de informação de marketing, a pesquisa de marketing, o planejamento de marketing e composto ou mix de marketing.

Quanto ao sistema de informação de marketing, destaca-se que o ambiente de marketing se caracteriza por constantes e rápidas mudanças nos meios sociais, culturais, econômicos e tecnológicos, em conjunto com as alterações que as próprias organizações passam internamente, que fazem da atividade de marketing mais arriscada e complexa. Para diminuir os riscos, é preciso dispor do máximo possível de conhecimento sobre estas variáveis (MATTAR, 1986).

A obtenção de informações faz parte do processo de tomada de decisão, sendo relevante extrair sentido destas informações, de modo a obter recursos e empregá-los na solução de problemas (JOCHIMS, 2008). Diante disto, faz-se necessária a aquisição, o processamento e a transmissão de informações de marketing precisas e oportunas (EZEKIEL; EZE; ANYADIGHIBE, 2013).

Neste contexto, um sistema de informação (SI) pode ser conceituado como "um conjunto de componentes inter-relacionados que coletam (ou recuperam), processam, armazenam e distribuem informações destinadas a apoiar a tomada de decisões, a coordenação e o controle de uma organização" (LAUDON; LAUDON, 2010, p. 12).

Diante das demandas por informações nos mais diversos níveis das empresas, existem os mais variados tipos de sistema. Deste modo, uma empresa típica conta com sistemas 
integrados em suas principais funções. Assim, insere-se o sistema de informação de marketing (SIM) (KOTLER; ARMSTRONG, 2007).

Com base em seus estudos, Jochims (2008) considera que o SIM objetiva possibilitar que os profissionais de marketing economizem esforços na busca e análise de informações e reduzam o tempo necessário para essas atividades, para que possam ser concentrar em sua atividade principal, que é fazer marketing.

Por outro lado, Kotler e Keller (2006, p. 71) ressaltam que um SIM moderno é desenvolvido a partir de registros internos da empresa (que permitem a análise de informações relevantes), atividades de inteligência de marketing (que agregam informações do dia a dia dos executivos) e pesquisas de marketing.

Malhotra (2012, p. 18) também indica a existência do sistema de suporte às decisões (SSD), que representa "um sistema integrado que inclui hardware, rede de comunicações, banco de dados, banco de modelos, banco de software e o usuário", possibilita que o responsável pelas decisões estabeleça uma interação direta com os bancos de dados e modelos de análise.

Considerando ainda a importância de informações relevantes e em tempo hábil para as decisões empresariais, destaca-se a pesquisa de marketing. Para tomar suas decisões, as organizações necessitam da disponibilização de informações específicas, que podem ser usadas para a composição de estratégias (AAKER; KUMAR; DAY, 2011). Para Malhotra (2012, p. 6) a pesquisa de marketing representa a "identificação, coleta, análise, disseminação e uso de informação de forma sistemática e objetiva para melhorar a tomada de decisões relacionadas com a identificação e solução de problemas e oportunidades de marketing”.

Pode-se utilizar as pesquisas de marketing em busca de informações para o lançamento de novos produtos, para monitorar a imagem da marca, para descobrir causas de diminuições em vendas, o impacto de comerciais, entre outros. No planejamento da pesquisa, alguns fatores a serem considerados são o tempo, a verba e a disponibilidade da empresa (LAS CASAS, 2012).

A pesquisa de marketing também mantém relação com o composto de marketing, já que este deve se adaptar as alterações do ambiente onde as empresas e consumidores convivem. Embora os gerentes possam controlar o composto, o mesmo não se aplica ao ambiente externo, que precisa ser conhecido para que o futuro possa ser planejado de maneira inteligente (MCDANIEL; GATES, 2006). 
Diferentes autores apontam diferentes etapas para a realização da pesquisa de marketing. Deste modo, apresenta-se na sequência as etapas propostas por Malhotra (2012), Aaker, Kumar e Day (2011) e Kotler e Armstrong (2007).

Quadro 2 - Etapas do processo de pesquisa de marketing

\begin{tabular}{|l|l|l|}
\hline \multicolumn{1}{|c|}{ Malhotra (2012) } & \multicolumn{1}{|c|}{ Aaker, Kumar e Day (2011) } & \multicolumn{1}{|c|}{ Kotler e Armstrong (2007) } \\
\hline Definição do problema. & Propósito de pesquisa. & $\begin{array}{l}\text { Definição do problema e dos } \\
\text { objetivos da pesquisa. }\end{array}$ \\
\hline $\begin{array}{l}\text { Desenvolvimento de uma } \\
\text { abordagem. }\end{array}$ & $\begin{array}{l}\text { Objetivo da pesquisa. } \\
\text { pesquisa para coletar dados. }\end{array}$ \\
\hline $\begin{array}{l}\text { Formulação da concepção de de } \\
\text { pesquisa. }\end{array}$ & $\begin{array}{l}\text { Estimativa do valor das } \\
\text { informações. }\end{array}$ & $\begin{array}{l}\text { Implementação do plano de } \\
\text { pesquisa (coleta e analise). }\end{array}$ \\
\hline $\begin{array}{l}\text { Trabalho de campo ou coleta de } \\
\text { dados. }\end{array}$ & Escolha da abordagem. & $\begin{array}{l}\text { Interpretação e apresentação dos } \\
\text { resultados. }\end{array}$ \\
\hline $\begin{array}{l}\text { Preparação e análise dos dados. } \\
\text { Preparação e apresentação do interpretação e utilização } \\
\text { relatório. }\end{array}$ & \begin{tabular}{l} 
\\
\hline Oos dados.
\end{tabular} & \\
\hline
\end{tabular}

Fonte: Adaptado de Malhotra (2012), Aaker, Kumar e Day (2011) e Kotler e Armstrong (2007)

A pesquisa de marketing pode influenciar fortemente o planejamento de marketing em suas estratégias para atender ao planejamento estratégico organizacional. O planejamento estratégico busca encontrar um plano para a sobrevivência e crescimento de longo prazo das organizações, alinhando fatores internos e externos (KOTLER; ARMSTRONG, 2007). Para a criação, entrega e comunicação de valor por parte do marketing, são necessárias diversas atividades, que necessitam de um planejamento estratégico como base e que, por sua vez, exige ações em três áreas-chave: "a primeira é gerenciar os negócios da empresa como uma carteira de investimentos. A segunda envolve a avaliação dos pontos fortes e fracos de cada negócio [...]. A terceira é estabelecer metas” (KOTLER; KELLER, 2006, p. 40).

Neste processo, o marketing desempenha um importante papel, portanto precisa ser realizado como uma parte integrante do planejamento estratégico e da elaboração do orçamento (WESTWOOD, 2007). Por meio do planejamento de marketing é possível alcançar uma gerência sensata de suas funções, atuar de modo sistemático para identificar ações possíveis, escolher quais seguir e programar custos para alcançar os objetivos. Diante da complexa interação entre fatores internos e externos, o planejamento de marketing torna-se essencial. E embora a intuição, experiência e sensibilidade possam contribuir, os administradores precisam de um entendimento racional sobre estas variáveis (MCDONALD; WILSON, 2013).

Para o planejamento de marketing, realiza-se um plano de marketing, que consiste em um documento que, de maneira sucinta, explana o conhecimento que o profissional de marketing possui sobre o mercado e como a empresa tenciona alcançar seus objetivos 
(KOTLER; KELLER, 2006). Tal plano conta com resumo executivo e sumário, análise da situação, estratégia de marketing, projeções financeiras, e por fim, a etapa de controle.

Lima et al. (2007) indicam a importância de programar atividades, prazos, responsáveis e recursos, definir variáveis de controle, metas e a regularidade para a verificação de desempenho. Na concepção de Hooley, Piercy e Nicouland, (2011), após definidas as estratégias, o marketing as transforma em esforços de mercado por meio do composto de marketing (produto, preço, praça e promoção).

As atividades de marketing são descritas tradicionalmente através do mix ou composto de marketing, que representa um conjunto de ferramentas de marketing empregadas para perseguir os objetivos de marketing (KOTLER; KELLER, 2006). De acordo com Urdan e Urdan (2013), o composto de marketing envolve questões táticas do trabalho do profissional de marketing.

O conceito de tal composto iniciou por volta de 1950, com o emprego de métodos mercadológicos no setor lucrativo, quando Neil N. Borden (1965 apud AMARAL, 2000), inspirado por Culligton, passou a utilizar o termo marketing mix em seus textos e aulas. Em 1960, Jerome E. McCarthy propôs a classificação do composto em 4Ps (Produto, Preço, Praça e Promoção).

Amaral (2000) apresenta a opinião de Lauterborn de que a teoria de McCarthy, válida no contexto de sua criação, teve seu método imposto de cima para baixo nas organizações, orientando-se mais para produtos do que para consumidores. Assim, propôs os 4Cs. O primeiro "C" representa Cliente, ao invés de Produto, seguido por Custo aos clientes em contrapartida a Preço, Conveniência no lugar de Ponto de Distribuição/Praça e Comunicação substituindo Promoção.

Também foram desenvolvidos outros diversos conceitos, mas Urdan e Urdan (2013) indicam que, de modo geral, é suficiente considerar o conceito de McCarthy, sendo que ainda hoje, organizações não administram notavelmente os elementos dos 4Ps.

No quadro a seguir, apresentam-se as principais decisões referentes ao composto de marketing, segundo Las Casas (2012) e Kotler e Keller (2006). 
Quadro 3-Composto de marketing e suas subdivisões

\begin{tabular}{|c|c|c|c|}
\hline Produto & Preço & $\begin{array}{c}\text { Distribuição (ponto-de- } \\
\text { venda) }\end{array}$ & Promoção \\
\hline $\begin{array}{ll}\text { Testes } & \mathrm{e} \\
\text { desenvolvimento }\end{array}$ & Política de preços & Canais de distribuição & Promoção de vendas \\
\hline $\begin{array}{ll}\text { Variedade } & \text { de } \\
\text { produtos/serviços } & \end{array}$ & $\begin{array}{l}\text { Métodos para } \\
\text { determinação de preços }\end{array}$ & Distribuição física & Propaganda \\
\hline Qualidade & Descontos & Variedades & Força de vendas \\
\hline Design & Concessões & Locais & Relações públicas \\
\hline Características & $\begin{array}{l}\text { Condições } \\
\text { financiamento }\end{array}$ & Transportes & \multirow[t]{8}{*}{ Marketing direto } \\
\hline Embalagem & \multirow[t]{7}{*}{ Prazo de pagamento } & Armazenagem & \\
\hline Nome da marca & & \multirow[t]{6}{*}{ Centro de Distribuição } & \\
\hline Tamanhos & & & \\
\hline Serviços & & & \\
\hline Assistência técnica & & & \\
\hline Garantias & & & \\
\hline Devoluções & & & \\
\hline
\end{tabular}

Fonte: Adaptado de Las Casas (1997 apud LAS CASAS, 2012) e Kotler e Keller (2006)

Após abordar as principais atividades que compõem a gestão do marketing, em seguida serão conceituados elementos referentes às organizações cooperativas.

\subsection{O COOPERATIVISMO E A GESTÃO DO MARKETING}

A Lei $n^{\circ}$ 5.764/71, que trata da Política Nacional do cooperativismo, do regime jurídico das sociedades cooperativas e dá outras providências, define as cooperativas como "sociedades de pessoas, com forma e natureza jurídica próprias, de natureza civil, não sujeitas a falência, constituídas para prestar serviços aos associados, distinguindo-se das demais sociedades". Para Lima Neto (2006, p. 148) a cooperativa é "uma associação de pessoas que voluntariamente se unem para satisfazer aspirações e necessidades econômicas, sociais e culturais comuns, através de uma empresa de propriedade comum", com gestão democrática e sem fins lucrativos. Segundo o Cooperative Development Institute (2016), as cooperativas são propriedade de seus membros, que podem ser consumidores, produtores, agricultores, trabalhadores, entre outros.

O cooperativismo está fundamentado em sua doutrina, inserida na Doutrina Econômica, ou seja, a doutrina cooperativista visa correlacionar o âmbito social e o econômico (CENZI, 2002). De acordo com Carvalho (2006), a natureza das cooperativas não admite uma cultura individualista, sendo que seus membros buscam crescimento econômico, social e educacional comum. 
Tais organizações agem de acordo com "valores de auto-ajuda, responsabilidade própria, democracia, igualdade, equidade e solidariedade. [...] os membros da cooperativa acreditam nos valores éticos de honestidade, sinceridade, responsabilidade social e preocupação com os outros" (SCHMIDT; PERIUS, 2003, p. 63); e os princípios do cooperativismo colocam estes valores em prática.

Tais princípios, definidos em 1995 pela International Cooperative Alliance (ICA), são: Adesão voluntária e livre; Gestão democrática pelos membros; Participação econômica dos membros; Autonomia e independência; Educação, formação e informação; Intercooperação; e Interesse pela comunidade (CRÚZIO, 2005; ICA, 2016).

Quanto ao marketing nestas instituições, Crúzio (2003) aponta o marketing social, que se fundamenta nos valores dos primeiros movimentos cooperativistas. Kotler e Lee (2011, p. 26) conceituam o marketing social como "esforços focados em influenciar comportamentos que vão melhorar a saúde, evitar acidentes, proteger o meio ambiente e contribuir com a sociedade em geral". Assim, consideram que o marketing social constitui apenas parte das atividades de marketing dessas organizações.

Oliveira (2012) trata do marketing total nas cooperativas como um de seus componentes estratégicos sendo um "processo interativo de todas as atividades e unidades organizacionais da cooperativa com as necessidades e expectativas dos cooperados e mercados atuais e potenciais" (OLIVEIRA, 2012, p. 45). Reis et al. (2008) acredita que a administração de marketing nas cooperativas representa um conjunto de ações referentes ao planejamento, organização, direção e controle do âmbito comercial da organização.

Segundo Reis et al. (2008), a maioria das cooperativas atuam com departamentos próprios de marketing para realizar a comunicação com o público. Atualmente, as cooperativas voltam-se para o diferencial e o posicionamento do mercado, pois não basta ser uma cooperativa, é necessário diferenciar-se das demais cooperativas. Neste processo, o marketing é fundamental, portanto, a empresa precisa manter uma sintonia total com seus associados e cooperados, sua equipe de colaboradores e disponibilizar os melhores serviços.

Machado Filho, Marino, Conejero (2004), sob outro ponto de vista, consideram que a gestão de marketing nas cooperativas geralmente é relegada a um plano inferior, e suas atividades são, na prática, relacionadas apenas a comercialização da produção.

Após a explanação sobre as ações do marketing e os aspectos referentes ao cooperativismo, o tópico seguinte contém os procedimentos metodológicos empregados neste estudo. 


\section{METODOLOGIA}

Neste capítulo serão apresentados os procedimentos metodológicos adotados para a execução deste estudo. Para o alcance dos objetivos propostos, realizou-se uma revisão sistemática da literatura. Este procedimento apresenta as seguintes etapas: 1) Formulação da pergunta; 2) Localização e seleção dos estudos; 3) Avaliação crítica dos estudos; 4) Coleta de dados; 5) Análise e apresentação dos dados; 6) Interpretação dos dados; 7) Aprimoramento e atualização da revisão (JACKSON et al., 2004 apud TOSTA, 2012).

A seleção das revistas ocorreu conforme classificação no Sistema Integrado Capes (SICAPES), no site WebQualis. Deste modo, foram selecionadas 19 revistas que apresentam estrato A2 e revistas B1 e B2, tendo em vista sua relação à área de Administração, ou a questões regionais e de desenvolvimento, já que as cooperativas exercem um relevante papel nas regiões em que se localizam.

Esta pesquisa foi efetuada a partir do levantamento bibliográfico eletrônico de artigos publicados nas revistas selecionadas, entre 1995 e o primeiro semestre de 2015, em português. Buscou-se por determinados termos, a saber, sistema de informação, sistemas de informação, pesquisa de marketing, pesquisa em marketing, planejamento em marketing, planejamento de marketing, plano de marketing, composto de marketing e mix. No caso dos termos "sistema de informação", "sistemas de informação" e "mix", após a busca inicial pelos artigos, selecionou-se os que tratavam de marketing e dentre estes, em todas as palavras-chave, buscou-se por artigos que abordavam o tema cooperativismo ou se relacionavam a cooperativas.

A partir da escolha das revistas, foram selecionados seis artigos para avaliação, que ocorreu por meio da leitura dos estudos, seguida pela a elaboração de quadros sinópticos com as informações sobre os autores, títulos, anos de publicação e revistas em que os estudos foram publicados, bem como as palavras-chave e autores mais citados nestas obras. Procurouse identificar os seguintes aspectos: a vinculação dos autores com instituições de ensino, os objetivos pretendidos pelos trabalhos, as metodologias aplicadas e os principais resultados alcançados, seguidos por uma análise comparativa dos resultados.

\section{RESULTADOS E DISCUSSÕES}


Visando atender ao objetivo deste estudo, foram analisadas 19 revistas científicas nacionais. Realizou-se a busca por artigos referentes aos temas estudados (sistema de informação de marketing, pesquisa, planejamento e composto ou mix de marketing) em cada um dos periódicos. Na sequência, o Quadro 4 expõe as revistas selecionadas, e seus respectivos estratos.

Quadro 4 - Revistas selecionadas e seus respectivos estratos

\begin{tabular}{|l|c|}
\hline \multicolumn{1}{|c|}{ Revista } & Estrato \\
\hline Revista de Administração Contemporânea (RAC) & $\mathrm{A} 2$ \\
\hline Revista de Administração de Empresas (RAE) & $\mathrm{A} 2$ \\
\hline Revista de Administração da Universidade de São Paulo (RAUSP) & $\mathrm{A} 2$ \\
\hline Revista de Administração FACES Journal & $\mathrm{B} 1$ \\
\hline Gestão \& Regionalidade (G\&R) & $\mathrm{B} 1$ \\
\hline Revista de Administração e Inovação (RAI) & $\mathrm{B} 1$ \\
\hline Revista de Administração Mackenzie (RAM) & $\mathrm{B} 1$ \\
\hline Revista Eletrônica de Administração (REAd) & $\mathrm{B} 1$ \\
\hline Revista Eletrônica do Alto Vale do Itajaí (REAVI) & $\mathrm{B} 1$ \\
\hline Revista Brasileira de Gestão e Desenvolvimento Regional (G\&DR) & $\mathrm{B} 1$ \\
\hline Revista de Administração da UFSM (ReA UFSM) & $\mathrm{B} 1$ \\
\hline Revista de Administração da Unimep (RAU) & $\mathrm{B} 1$ \\
\hline Revista USP & $\mathrm{B} 2$ \\
\hline Revista de Administração, Contabilidade e Economia (RACE) & $\mathrm{B} 2$ \\
\hline Revista Eletrônica de Ciência Administrativa (RECADM) & $\mathrm{B} 2$ \\
\hline Revista de Gestão USP (REGE) & $\mathrm{B} 2$ \\
\hline Revista Brasileira de Marketing (REMark) & B2 \\
\hline Revista Pensamento Contemporâneo em Administração (RPCA) & B2 \\
\hline Revista de Gestão Organizacional (RGO) & \\
\hline
\end{tabular}

Fonte: Elaborado pelas autoras (2015)

Apresenta-se, a seguir, os artigos selecionados para análise, com o intuito de descrever suas características principais, tais como os autores, sua formação/vinculação, ano de publicação das obras, palavras-chave, objetivos dos estudos, aspectos metodológicos, principais resultados alcançados e referências empregadas.

\subsection{ANÁLISE E APRESENTAÇÃO DAS CARACTERÍSTICAS DOS ESTUDOS}

Após a realização de buscas nas revistas apresentadas no Quadro 4, foram selecionados ao todo seis artigos que tratam das atividades de marketing consideradas nesta revisão sistemática, em organizações cooperativas. O quadro a seguir mostra a listagem dos artigos selecionados. 
Quadro 5 - Artigos selecionados e respectivas informações

\begin{tabular}{|c|l|c|c|}
\hline Autores & \multicolumn{1}{|c|}{ Título do artigo } & Ano & Fonte \\
\hline Batalha e Silva & Marketing \& Agribusiness: um enfoque estratégico & 1995 & RAE \\
\hline Delgado e Cruz & $\begin{array}{l}\text { As inovações no setor de laticínios: o caso francês do } \\
\text { Grupo Cooperativo 3 }\end{array}$ & 2009 & REAd \\
\hline $\begin{array}{c}\text { Marino, Costa e } \\
\text { Mondo }\end{array}$ & $\begin{array}{l}\text { Ampliando o portfolio de serviços: um estudo sobre o } \\
\text { plano odontológico Unimed na grande Florianópolis - } \\
\text { SC }\end{array}$ & 2011 & RAU \\
\hline $\begin{array}{c}\text { Diniz, Giarola, } \\
\text { Balbin, Ferreira e } \\
\text { Nazareth }\end{array}$ & $\begin{array}{l}\text { A estratégia empresarial e o marketing estratégico } \\
\text { comoperativista: uma pesquisa aplicada sob o enfoque da } \\
\text { teoria dos jogos dorma de fortalecimento da doutrina }\end{array}$ & 2013 & FACES \\
\hline $\begin{array}{c}\text { Severo, Tinoco, } \\
\text { Claro, Schneider e } \\
\text { Yoshitake }\end{array}$ & $\begin{array}{l}\text { Educação cooperativa na busca pela construção e } \\
\text { vivência de atitudes e valores de cooperação e } \\
\text { cidadania voltados ao desenvolvimento regional }\end{array}$ & 2014 & RAU \\
\hline $\begin{array}{c}\text { Prado, Ferrugini, } \\
\text { Souza, Paiva e } \\
\text { Vilas Boas }\end{array}$ & $\begin{array}{l}\text { Reconhecendo o valor do cooperativismo sob a ótica } \\
\text { da cadeia meios-fins }\end{array}$ & 2014 & $\begin{array}{c}\text { FACES } \\
\text { Journal }\end{array}$ \\
\hline
\end{tabular}

Fonte: Elaborado pelas autoras (2015)

Estes artigos foram escritos por 22 autores, dos quais, 14 são homens e oito mulheres. Utilizaram-se ao todo 165 referências, com uma média simples de 28 referências por artigo. Destaca-se que, dentre os títulos dos artigos escolhidos, deparou-se com a palavra marketing em apenas dois deles, enquanto termos referentes ao cooperativismo estão presentes em quatro.

Foram encontrados artigos publicados de 1995 a 2014. No ano de 1995 foi encontrada uma publicação e não foram apresentadas publicações sobre os assuntos analisados de 1996 a 2008, havendo uma publicação nos seguintes anos: 2009, 2011, 2013 e duas publicações em 2014. O Gráfico 1, na sequência, demonstra a quantidade de artigos publicados ao passar dos anos. 
Gráfico 1 - Período e quantidade de publicações selecionadas

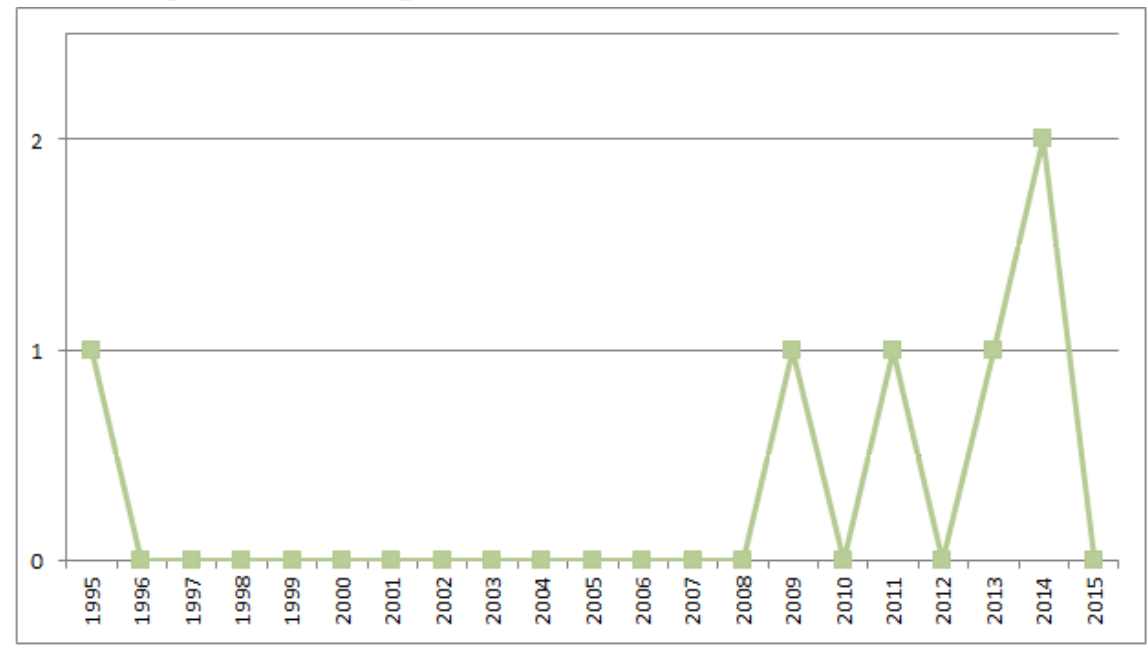

Fonte: Elaborado pelas autoras (2015)

O Gráfico 1 demonstra que nas revistas pesquisadas, 2014 apresentou o maior número de publicações sobre o assunto pesquisado, sendo uma publicação na Revista de Administração da Unimep (RAU) e outra na Revista de Administração FACES Journal.

Em seguida, o quadro demonstra as palavras-chave e principais autores citados por estas pelas obras.

Quadro 6 - Palavras-chave e autores mais citados por artigo

\begin{tabular}{|c|c|c|}
\hline Autores & $\begin{array}{l}\text { Palavras-chave } \\
\end{array}$ & Principais autores citados \\
\hline $\begin{array}{l}\text { Batalha e Silva } \\
\text { (1995) }\end{array}$ & $\begin{array}{l}\text { Mercado, agribusiness, marketing, sistema } \\
\text { agroindustrial, cadeia agroindustrial, } \\
\text { complexo agroindustrial. }\end{array}$ & $\begin{array}{l}\text { Batalha (1993), Porter (1992) e } \\
\text { Filser (1985). }\end{array}$ \\
\hline $\begin{array}{l}\text { Delgado e Cruz } \\
(2009)\end{array}$ & $\begin{array}{l}\text { Inovações, organizações cooperativas, setor } \\
\text { de laticínios, França. }\end{array}$ & $\begin{array}{l}\text { Schumpeter (1934), Freeman e } \\
\text { Perez (1988), Damanpour e } \\
\text { Evan (1984). }\end{array}$ \\
\hline $\begin{array}{l}\text { Marino, Costa e } \\
\text { Mondo (2011) }\end{array}$ & $\begin{array}{l}\text { Plano Odontológico, Plano de Saúde, } \\
\text { Pesquisa de Intenção de Compra, } \\
\text { Unimed, Serviços. }\end{array}$ & $\begin{array}{l}\begin{array}{l}\text { Lovelock } \\
\text { (2003), Grönroos })\end{array} \text { Zeithaml } \\
\text { Cobra (2003), } \\
\text { Armstrong (1986), Kotler e } \\
\text { (1998). }\end{array}$ \\
\hline $\begin{array}{l}\text { Diniz, Giarola, } \\
\text { Balbin, Ferreira e } \\
\text { Nazareth }(2013)\end{array}$ & $\begin{array}{l}\text { Infidelidade nas cooperativas. Entressafra de } \\
\text { leite. Teoria dos jogos. Estratégia } \\
\text { empresarial. Marketing estratégico. }\end{array}$ & 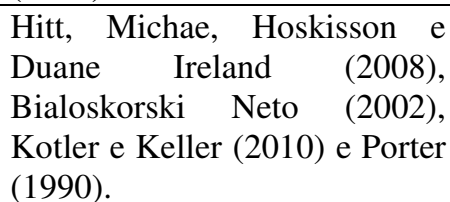 \\
\hline $\begin{array}{l}\text { Severo, Tinoco, } \\
\text { Claro, Schneider e } \\
\text { Yoshitake (2014) } \\
\end{array}$ & $\begin{array}{l}\text { Desenvolvimento Regional. } \text { Educação } \\
\text { Cooperativa. Cooperativas de Crédito. }\end{array}$ & $\begin{array}{l}\text { Ulrich (2010), Ashley (2005), } \\
\text { Melo Neto (2004) e Pinho } \\
\text { (1982). }\end{array}$ \\
\hline $\begin{array}{l}\text { Prado, Ferrugini, } \\
\text { Souza, Paiva e Vilas } \\
\text { Boas }(2014)\end{array}$ & $\begin{array}{l}\text { Cooperativismo. } \quad \text { Agronegócio. } \\
\text { meios-fim. Laddering. Valores. }\end{array}$ & $\begin{array}{l}\text { Reynolds e Gutman (1988), } \\
\text { Veludo-De-Oliveira e Ikeda } \\
\text { (2008), Ikeda e Veludo-De- } \\
\text { Oliveira (2008) e Gutman } \\
(1982)\end{array}$ \\
\hline
\end{tabular}

Fonte: Elaborado pelas autoras (2015) 
Mediante o Quadro 6, o termo marketing encontra-se presente nas palavras-chave de apenas dois artigos, enquanto termos relacionados ao cooperativismo são encontrados em quatro artigos.

O primeiro artigo a ser tratado é o de Batalha e Silva (1995), os dois autores se apresentam como professores, sendo o primeiro adjunto e o segundo assistente, do Departamento de Engenharia de Produção da Universidade Federal de São Carlos (UFSCar). Este artigo teve como objetivo demonstrar que o enfoque, as ferramentas e as variáveis a se considerar, quando se trata de mercados que constituem uma cadeia agroindustrial, se alteram de acordo com sua posição nesta cadeia e no mercado para o qual as estratégias de marketing se voltam.

Nesta obra exploratória, os autores apontam não ser possível definir instrumentos homogêneos de marketing que possam ser empregados em todos os mercados participantes do Sistema Agroindustrial, pois cada um deles demanda a adaptação de diversas ferramentas de marketing genérico. No entanto, pode-se adaptar e utilizar métodos mercadológicos clássicos de análise e recomendações.

O artigo seguinte é de Delgado e Cruz (2009), professores vinculados a Universidade de Fortaleza (Unifor). O artigo discorre sobre a temática de inovação em cooperativas, buscando analisar e identificar as inovações em uma cooperativa localizada na França, atuante no setor de laticínios. Tratam de aspectos de P\&D (pesquisa e desenvolvimento), inovações tecnológicas e de produtos, focando todo seu referencial teórico em conceitos referentes à inovação. A metodologia adotada caracteriza-se como qualitativa, descritiva e estudo de caso, as coletas de dados foram realizadas através de entrevistas semiestruturadas, observações e pesquisa documental. Os dados foram analisados por meio da transcrição literal das entrevistas, organização dos dados significantes e identificação, descrição e análise dos efeitos das ações da cooperativa.

Os autores apresentaram, como principais resultados, a observação de que o setor de laticínios depende de inovações incrementais, sendo que os impactos radicais se concentravam nos 15 anos anteriores; há uma vasta quantidade de inovações em termos de gestão, processos e produtos e investimentos em tecnologia, e por fim, de que existe um nicho de mercado, pouco explorado pelas organizações brasileiras, a saber, o de produtos ambiental e socialmente corretos.

No artigo de Marino, Costa e Mondo (2011), da RAU, os dois primeiros autores apresentam-se como vinculados a Universidade do Estado de Santa Catarina (UDESC) e o último ao Complexo de Ensino Superior de Santa Catarina (Cesusc). O artigo teve como ReFAE - Revista da Faculdade de Administração e Economia, v. 9, n. 2, p. 01-25, 2019 
objetivo verificar a possibilidade de expandir o portfólio de serviços odontológicos da Unimed Grande Florianópolis, tratando, em seu referencial teórico, do marketing de serviços, a perspectiva do cliente e outros elementos relacionados à prestação de serviços. Aplicou-se pesquisa quantitativa-descritiva e estudo de caso. Empregou-se uma amostra de 400 questionários, respondidos por clientes dos planos de saúde desta organização, com mais de 18 anos, e o tratamento de dados foi realizado através do software Statistical Packge for the Social Science (SPSS) 15.0, sendo aplicadas medidas estatísticas, tais como médias, desviospadrões e frequências, além de se empregarem ferramentas de tabelas cruzadas.

O resultado principal do estudo indicou uma forte intenção de compra de um plano odontológico, havendo, portanto, possibilidade para ampliação da oferta dos serviços principais de saúde da organização.

$\mathrm{O}$ artigo selecionado na sequência tem como autores Diniz, Giarola, Balbin, Ferreira e Nazareth (2013). A primeira autora foi declarada como vinculada ao Instituto Federal de Educação, Ciência e Tecnologia do Triângulo Mineiro (IFTM), os dois seguintes à Universidade Federal de Uberlândia (UFA) e os dois últimos a Universidade Federal de Lavras (UFLA). A pesquisa expos o objetivo de "analisar, sob o enfoque da Teoria dos Jogos, o problema da infidelidade dos cooperados nas organizações cooperativistas, a fim de minimizá-lo por meio da Estratégia Empresarial e do Marketing Estratégico" abordando as Forças de Porter e o Marketing de Relacionamento (DINIZ et al., 2013, p. 67). A fundamentação teórica abordou temas como: a cooperativa e a relação com os associados, a infidelidade dos associados nas cooperativas de leite, a Teoria dos Jogos, a estratégia empresarial sob o ponto de vista das cooperativas, as Forças de Porter e o marketing de relacionamento, considerando aspectos quanto ao cooperativismo.

Em relação ao meio de investigação, constitui uma pesquisa bibliográfica e estudo de caso. Quanto aos objetivos, é uma pesquisa exploratória e descritiva. Empregou-se um questionário estruturado, fechado e autoaplicável, encaminhado a todos os associados, havendo um retorno de $12,5 \%$. O estudo indicou, entre outros aspectos, a infidelidade dos associados enfrentada pelas cooperativas de leite, principalmente na época de entressafra da produção. Uma das causas do surgimento de conflitos na cooperativa estudada é a falta de compartilhamento de informações, é tais problemas poderiam ser minimizados se a organização alterasse o foco de seu negócio na entressafra. Além disto, propôs-se a criação da missão e a definição do negócio, seguidas pelo uso de técnicas de marketing de relacionamento. 
Severo, Tinoco, Claro, Schneider e Yoshitake (2014, p. 3), são os autores do artigo seguinte. Severo e Schneider apresentam-se como vinculados a Universidade do Vale do Rio dos Sinos (UNISINOS), Tinoco a Faculdade Campo Limpo Paulista (FACCAMP), Claro a Universidade Federal de São Paulo (Unifesp), e Yoshitake a Faculdade ALFA. O estudo objetivou "analisar se o Programa de Educação Cooperativa, na visão dos professores, possibilita a construção e a vivência de atitudes e valores de cooperação e cidadania voltados para o desenvolvimento das comunidades onde atua". O referencial teórico abordou temas relativos à responsabilidade social e educação cooperativa.

Em relação ao aspecto metodológico, o estudo é caracterizado como quantitativo e qualitativo, de caráter aplicado e exploratório, com o uso de questionário semiestruturado. Para o tratamento dos dados o software Statistical Packge for the Social Science (SPSS) foi empregado. Indicou-se que os professores que atuam diretamente com o Programa de Educação Cooperativa acreditam que diversos aspectos são considerados satisfatórios, como a existência de um processo de comunicação claro e dinâmico. Por outro lado, foram identificados pontos merecedores de atenção, como a realização de palestras dirigidas aos professores, tratando de temas como integração entre comunidade, escola e o Programa, responsabilidade social, dificuldades encontradas em sala de aula e sugestões para reduzi-las. Averiguou-se que o Programa atua de maneira eficaz, sendo bem visto pelos professores.

No último artigo, de Prado, Ferrugini, Souza, Paiva e Vilas Boas (2014, p. 50-51) os quatro primeiros autores estão vinculados a Universidade Federal de Lavras (UFLA), enquanto o último a Universidade Federal de Alfenas - Campus Varginha (UNIFAL - MG). Os autores possuem o objetivo de "identificar a estrutura cognitiva de valor percebida pelos cooperados de uma cooperativa agropecuária localizada no Sul de Minas Gerais, servindo de referência para o desenvolvimento de estratégias, gerenciais e mercadológicas”, ponderando a percepção de valor dos cooperados. Na fundamentação teórica tratam-se conceitos referentes a valores pessoais, valores cooperativistas e o emprego da Teoria de Meios e Fins, pela abordagem laddering.

A pesquisa constitui um estudo de caso com cooperados de uma cooperativa agropecuária de Minas Gerais. Foi empregada a técnica de laddering, com entrevistas em profundidade com vinte e cinco cooperados, sistematizadas através da cadeia meios-fins. Trata-se de uma pesquisa exploratória e descritiva, com amostra não probabilística por conveniência, foram aplicadas entrevistas com roteiros semiestruturados, além de fazer uso de um questionário estruturado no início de cada entrevista, a fim de identificar o perfil dos 
cooperados. A tabulação dos dados contou com os softwares: Statistical Packge for the Social Science (SPSS) e Microsoft Office Excel 2007, além de adotar-se o software Mecanalystic.

Indicou-se que os mais importantes atributos que contribuem para a permanência dos cooperados na cooperativa são "Assistência Técnica", "Bolsão", "Facilidade/Comodidade ao cooperado", "Condições de Pagamento", "Armazenagem do Café" e, por último, "Comercialização de Café" e "Atendimento ao cooperado". Os cooperados acreditam que a cooperativa possibilita melhorias em sua qualidade de vida, interfere em sua felicidade e tranquilidade para a execução de suas atividades e o alcance de sua realização pessoal.

Após abordar cada um dos estudos selecionados, é possível estabelecer uma avaliação comparativa entre eles, apresentada a seguir.

\subsection{ANÁLISE COMPARATIVA DOS ESTUDOS}

Ao considerar os estudos analisados, observa-se que em um período de 20 anos (1995 até 2015), nestas revistas selecionadas, existem poucos artigos que demonstrem relação entre as atividades de marketing e as cooperativas ou que estudem este aspecto. Ressalta-se o longo período sem publicações acerca do assunto, de 1996 até 2008, seguido por um aumento gradativo da quantidade de publicações nos últimos cinco anos. Pode-se considerar, frente estes dados, que o interesse em aspectos referentes ao marketing em cooperativas vem aumentando lentamente nos últimos anos, embora ainda haja poucas publicações que considerem este tema nestas revistas.

Nota-se que dentre os seis artigos selecionados, não há repetição de nenhum dos autores. Os estudos advêm de instituições de ensino diversas, com destaque para a Universidade Federal de Lavras (UFLA), com vinculação de seis autores. As principais metodologias empregadas nos artigos foram pesquisas exploratórias e descritivas, qualitativas e estudos de caso.

Os artigos selecionados são encontrados em quatro revistas, das quais, três possuem classificação B1 e uma classificação A2. Destaca-se que as últimas quatro publicações são encontradas em duas revistas, a saber, a FACES Journal e a RAU, a primeira é uma publicação da Universidade FUMEC/FACES, enquanto a segunda é uma revista da Universidade Metodista de Piracicaba (Unimep). As outras duas revistas são a RAE, vinculada à Fundação Getúlio Vargas Escola de Administração de Empresas de São Paulo e a REAd vinculada à Escola de Administração da Universidade Federal do Rio Grande do Sul (UFRGS). 
Comparando-se as referências empregadas por cada um dos artigos, ressalta-se a diversificação de obras, sendo os nomes mais citados Gil (2002), Pinho (1982), além do emprego de três obras de Philip Kotler, a saber, Kotler e Keller (2010), Kotler e Armstrong (1998) e Kotler (1998) e três de Zylbersztajn (2012; 2002; 1993).

A partir da apresentação dos resultados obtidos com esta revisão sistemática, pode-se destacar que, dentre os artigos selecionados, os de Batalha e Silva (1995), Marino, Costa e Mondo (2009) e Diniz et al. (2013) demonstraram maior relação entre o cooperativismo e o marketing.

Após esta explanação, o tópico seguinte consiste nas considerações finais deste estudo.

\section{CONSIDERAÇÕES FINAIS}

O marketing constitui uma importante função gerencial que possibilita a melhor compreensão acerca dos consumidores e demais fatores presentes nos mercados, de modo que as organizações possam adequar suas habilidades às demandas existentes e entregar um valor superior. Dentre as diversas atividades e ferramentas envolvidas na gestão do marketing, este trabalho destacou o sistema de informação de marketing, a pesquisa de marketing, o planejamento de marketing e o composto ou mix de marketing, tendo em vista que estes elementos se inter-relacionam para possibilitar o alcance dos objetivos do marketing e das organizações.

Deste modo, o marketing nas cooperativas em determinados pontos se assemelha ao das demais empresas, ao mesmo tempo em que se difere, com vistas a atender a doutrina a os princípios que regem as cooperativas.

Considera-se que as cooperativas são importantes agentes sociais, promovendo melhorias na qualidade de vida de seus associados, buscando garantir retornos satisfatórios e proporcionar desenvolvimento para as regiões em que se inserem. Sendo o marketing responsável por estabelecer um relacionamento entre a empresa e seus consumidores e no caso das cooperativas, associados, considera-se que o desenvolvimento da gestão do marketing pode contribuir para estas organizações e para o alcance destes objetivos.

Diante disto, este estudo realizou uma revisão sistemática com o objetivo de investigar o perfil das pesquisas e a evolução do estudo do tema Marketing em Cooperativas, sob o 
ponto de vista das atividades referentes a sistema de informação de marketing, pesquisa de marketing, planejamento de marketing e composto ou mix de marketing.

A partir dos dados obtidos na revisão sistemática, espera-se que haja uma expansão no interesse pelo assunto estudado nos próximos anos, não apenas em quantidade de estudos, mas em profundidade do tema abordado. Destaca-se que, nos artigos selecionados, três deles apresentavam maior correlação entre o marketing e o cooperativismo, a saber, um relacionado às ferramentas de marketing no sistema agroindustrial, um referente ao marketing de serviços em organizações cooperativas e um voltado ao marketing de relacionamento. No entanto, observa-se relativa carência de estudos que tratem do papel estratégico do marketing nestas organizações e de sua relevância, aplicabilidade ou efetividade em questões referentes aos fatores internos e externos que interferem em seu funcionamento.

A partir desta revisão sistemática da literatura, é possível obter uma compreensão mais abrangente acerca das abordagens utilizadas nos estudos sobre marketing em cooperativas, bem como das perspectivas para futuras pesquisas. Como limitações da pesquisa, ressalta-se que esta revisão sistemática realizou buscas em revistas classificadas entre os estratos A2 a B2, entre 1995 e 2015. Deste modo, em pesquisas futuras pode-se sugerir o uso de uma gama maior de revistas, abarcando os estratos A1 a B5, o que pode contribuir com novas perspectivas para o tema estudado.

\section{REFERÊNCIAS}

AAKER, D. A.; KUMAR, V.; DAY G. S. Pesquisa de marketing. 2. ed. São Paulo: Atlas, 2011.

AMA - American Marketing Association. 2013. Disponível em: $<$ https://www.ama.org/AboutAMA/Pages/Definition-of-Marketing.aspx >. Acesso em: 20 mar. 2016.

AMARAL, S. A. Do. Os 4Ps do composto de marketing na literatura de ciência da informação. Transinformação, Campinas, v. 12, n. 2, p. 51-60, dez. 2000. Disponível em: $<$ http://www.scielo.br/scielo.php?script=sci_arttext\&pid=S010337862000000200004\&lng=en\&nrm=iso >. Acesso em: 05 abr. 2015.

BATALHA, M. O.; SILVA, A. L. da. Marketing e Agribusiness: um enfoque estratégico. Revista de Administração de Empresas, São Paulo, v. 35, n. 5, p. 30-39, set./out. 1995. Disponível em: <http://rae.fgv.br/sites/rae.fgv.br/files/artigos/10.1590_S003475901995000500005.pdf>. Acesso em: 29 mar. 2015.

ReFAE - Revista da Faculdade de Administração e Economia, v. 9, n. 2, p. 01-25, 2019 
BRASIL. Lei $\mathrm{n}^{\circ}$ 5.764, de 16 de dezembro de 1971. Define a Política Nacional de Cooperativismo, institui o regime jurídico das sociedades cooperativas, e dá outras providências. Lei $\mathbf{N}^{\mathbf{0}} \mathbf{5 . 7 6 4}$, de 16 de Dezembro de 1971. Brasília, Disponível em: $<$ http://www.planalto.gov.br/ccivil_03/leis/15764.htm>. Acesso em: 14 nov. 2014.

CARVALHO, A. D. C. The Cooperative Development and Strategy. International Journal of Accounting and Financial Reporting, [S. 1.], v. 2, n. 1, p. 191- 202, 2012. Disponível em: $<$ http://www.macrothink.org/journal/index.php/ijafr/article/view/1563/1418 >. Acesso em: 14 fev. 2016.

CENZI, N. L. Cooperativismo: desde as origens ao Projeto de Lei da Reforma do Sistema Cooperativo Brasileiro. Curitiba: Juruá, 2012.

COBRA, M. Marketing básico: uma perspectiva brasileira. 4. ed. São Paulo: Atlas, 2011.

COOPERATIVE Development Institute. About Co-ops. Disponível em:

<http://www.cdi.coop/resource-center/about-co-ops/>. Acesso em: 14 fev. 2016.

CRÚZIO, H. de O. Como organizar e administrar uma cooperativa: uma alternativa para o desemprego. 4 ed. Rio de Janeiro: Editora FGV, 2005

Marketing social e ético nas cooperativas. Rio de Janeiro: Editora FGV, 2003.

DELGADO, N. A.; CRUZ, L. B. As inovações no setor de laticínios: o caso francês do grupo cooperativa 3A. Revista Eletrônica de Administração, [S.1.], v. 15, n. 3, p. 531-555, set./dez. 2009. Disponível em:

$<$ http://seer.ufrgs.br/index.php/read/article/view/39017/25060>. Acesso em: 29 mar. 2015.

DINIZ, P. C. de O. C. et al. A estratégia empresarial e o marketing estratégico como forma de fortalecimento da doutrina cooperativista: uma pesquisa aplicada sob o enfoque da teoria dos jogos. Revista de Administração Faces Journal, Belo Horizonte, v. 12, n. 3, p. 64-81, jul./set. 2013. Disponível em: <http://www.fumec.br/revistas/facesp/article/view/1382/1311>. Acesso em: 29 mar. 2015.

EZEKIEL, M. S.; EZE, J. F.; ANYADIGHIBEJ. A. A Study of Marketing Information System (MIS) As a Contributory Factor in the Performance of Selected Transport Companies in Calabar Metropolis. American Journal of Tourism Research, vol. 2, n. 2, p. 154-159 2013.

FERRELL, O. C.; HARTLINE, M. D. Estratégia de marketing. São Paulo: Pioneira Thomson Learning, 2005.

G\&DR - Revista Brasileira de Gestão e Desenvolvimento Regional. Disponível em: $<$ http://www.rbgdr.net/revista/index.php/rbgdr>. Acesso em: 29 mar. 2015.

G\&R - Gestão \& Regionalidade. Disponível em:

$<$ http://seer.uscs.edu.br/index.php/revista_gestao $>$. Acesso em: 29 mar. 2015. 
HOOLEY, G.; PIERCY, N. F.; NICOULAUD, B. Estratégias de marketing e posicionamento competitivo. 4. ed. São Paulo: Pearson Prentice Hall, 2011.

ICA - International Co-operative Alliance. Disponível em: $<$ http://ica.coop/en/whats-coop/co-operative-identity-values-principles>. Acesso em: 20 mar. 2016.

JOCHIMS, M. Z. Sistemas de Informação de Marketing: conceitos e práticas. 2008. 60 f. TCC (Graduação) - Curso de Administração, Universidade Federal do Rio Grande do Sul, Porto Alegre, 2008. Disponível em:

<http://www.lume.ufrgs.br/bitstream/handle/10183/18092/000685842.pdf?...1 >. Acesso em: 14 nov. 2014.

KOTLER, P.; ARMSTRONG, G. Princípios de marketing. 12. ed. São Paulo: Pearson Prentice Hall, 2007.

KOTLER, P.; KELLER, K. L. Administração de marketing: a bíblia do marketing. 12. ed. São Paulo: Prentice Hall Brasil, 2006.

KOTLER, P.; LEE, N. R. Marketing social: influenciando comportamentos para o bem. 3. ed. Porto Alegre: Bookman, 2011.

LAS CASAS, A. L. Administração de marketing: conceitos, planejamento e aplicações à realidade brasileira. São Paulo: Atlas, 2012.

LAUDON, K.; LAUDON, J. Sistemas de informações gerenciais. 9. ed. São Paulo: Pearson Prentice Hall, 2010.

LIMA NETO, A. Cooperativas de trabalho. Curitiba: Juruá, 2006.

MACHADO FILHO, C. A. P.; MARINO, M. K.; CONEJERO, M. A. Gestão estratégica em cooperativas agroindustriais. Caderno de pesquisas em Administração, São Paulo, v. 11, n. 2, p. 61-69, abr./jun. 2004. Disponível em:

<http://www.regeusp.com.br/arquivos/v11n2art5.pdf>. Acesso em: 25 ago. 2014.

MARINO, F.; COSTA, J. I. P. da.; MONDO, T. S. Ampliando o portfólio de serviços: um estudo sobre o plano odontológico Unimed na Grande Florianópolis - SC. Revista de Administração da UNIMEP, [S.1.], v. 9, n. 1, p. 131-145, jan./abr. 2011. Disponível em: $<$ http://www.regen.com.br/ojs/index.php/regen/article/view/297/460>. Acesso em: 29 mar. 2015 .

MATTAR, F.N. SIM - Sistemas de Informação de Marketing. Revista Mercado Global, n. 67, p. 24-45, março/abril 1986. Disponível em:

<http://www.fauze.com.br/DOCUMENTOS/SIM.pdf >. Acesso em: 14 nov. 2014.

MCDANIEL, C. D; GATES, R. Pesquisa de marketing. São Paulo: Thomson Learning, 2006.

MCDONALD, M.; WILSON, H. Planos de marketing. Rio de Janeiro: Elsevier, 2013. 
MEDEIROS, M. de L. et al. Administração e Políticas Públicas em Educação: uma revisão sistemática da produção do EnANPAD e do EnAPG de 1997 a 2009. Revista de Ciências da Administração, Florianópolis, v. 13, n. 30, p. 61-87, maio/ago., 2011. Disponível em: <http://www.redalyc.org/pdf/2735/273520054004.pdf>. Acesso em: 18 maio 2015.

OLIVEIRA, D. de P. R de. Manual de gestão das cooperativas: uma abordagem prática. 6 . ed. São Paulo: Atlas, 2012.

PRADO, A. S. et al. Reconhecendo o valor do cooperativismo sob a ótica da cadeia meiosfins. Revista de Administração Faces Journal, Belo Horizonte, v. 13, n. 3, p. 47-65, jul./set. 2014. Disponível em: <http://www.fumec.br/revistas/facesp/article/view/1816/1582>. Acesso em: 29 mar. 2015

RAC - Revista de Administração Contemporânea. Disponível em:

$<$ http://www.anpad.org.br/periodicos/content/frame_base.php?revista=1>. Acesso em: 29 mar. 2015.

RACE - Revista de Administração, Contabilidade e Economia. Disponível em: $<$ http://editora.unoesc.edu.br/index.php/race >. Acesso em: 30 mar. 2015.

RAE - Revista de Administração de Empresas. Disponível em: <http://rae.fgv.br/rae > Acesso em: 29 mar. 2015.

RAI - Revista de Administração e Inovação. Disponível em: $<$ http://www.revistarai.org/rai >. Acesso em: 29 mar. 2015.

RAM - Revista de Administração Mackenzie. Disponível em: $<$ http://editorarevistas.mackenzie.br/index.php/RAM>. Acesso em: 29 mar. 2015.

RAU - Revista de Administração da Unimep. Disponível em: <http://www.raunimep.com.br/ojs/index.php/regen/index>. Acesso em: 29 mar. 2015.

RAUSP - Revista de Administração da Universidade de São Paulo. Disponível em: $<$ http://www.rausp.usp.br/>. Acesso em: 29 mar. 2015.

ReA UFSM - Revista de Administração da UFSM. Disponível em:

$<$ http://cascavel.ufsm.br/revistas/ojs-2.2.2/index.php/reaufsm>. Acesso em: 29 mar. 2015.

REAd - Revista Eletrônica de Administração. Disponível em: <http://www.seer.ufrgs.br/read/>. Acesso em: 29 mar. 2015.

REAVI - Revista Eletrônica do Alto Vale do Itajaí. Disponível em: $<$ http://www.revistas.udesc.br/index.php/reavi >. Acesso em: 29 mar. 2015.

RECADM - Revista Eletrônica de Ciência Administrativa. Disponível em:

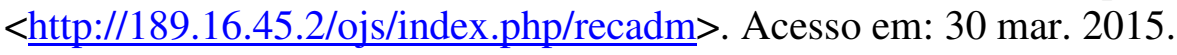

REGE - Revista de Gestão USP. Disponível em: <http://www.regeusp.com.br/>. 30 mar. 2015. 
REIS, G. de C. dos. et al. Marketing para cooperativas: CAMDA Cooperativa Agrícola Mista de Adamantina Lins - SP. 2008. 87 f. TCC (Graduação) - Curso de Administração, Centro Universitário Católico Salesiano Auxilium, Lins, 2008. Disponível em: $<$ http://www.unisalesiano.edu.br/biblioteca/monografias/46221.pdf $>$. Acesso em: 14 nov. 2014.

REMark - Revista Brasileira de Marketing. Disponível em: $<$ http://www.revistabrasileiramarketing.org/ojs-2.2.4/index.php/remark>. Acesso em: 30 mar. 2015.

REVISTA de Administração FACES Journal. Disponível em: <http://www.fumec.br/revistas/facesp>. Acesso em: 29 mar. 2015.

REVISTA USP. Disponível em: <http://www.revistas.usp.br/revusp > Acesso em: 30 mar. 2015.

RGO - Revista de Gestão Organizacional. Disponível em:

<http://bell.unochapeco.edu.br/revistas/index.php/rgo> 30 mar. 2015.

SAMPAIO, D. de O.; DIAS, C. L. Eficácia e eficiência da empresa, inovação e experiências na integração cooperativa. In.: Encontro de Pesquisadores Latino-Americanos de Cooperativismo, 5., 2008, Ribeirão Preto, Anais... Ribeirão Preto: Encontro de Pesquisadores Latino-Americanos de Cooperativismo, 2008. Disponível em: $<$ http://www.fundace.org.br/cooperativismo/arquivos_pesquisa_ica_la_2008/070sampaio.pdf>. Acesso em: 14 nov. 2014.

SCHMIDT, D.; PERIUS, V. Cooperativismo e cooperativa. In: CATTANI, A. D. (Org.). A outra economia. Porto Alegre: Veraz, 2003, p. 63-71.

SEVERO, P. S. et al. Educação cooperativa na busca pela construção e vivência de atitudes e valores de cooperação e cidadania voltados ao desenvolvimento regional. Revista de Administração da UNIMEP, [S.1.], v. 12, n. 1, p. 159-177, jan./abr. 2014. Disponível em: $<$ http://www.regen.com.br/ojs/index.php/regen/article/view/744/559 >. Acesso em: 29 mar. 2015.

SICAPES - Sistema Integrado Capes. Webqualis. Disponível em:

$<$ http://qualis.capes.gov.br/webqualis/publico/pesquisaPublicaClassificacao.seam?conversatio nPropagation=begin $>$. Acesso em: 28 mar. 2015.

SOUZA, T. de. Uma estratégia de marketing para cooperativas de artesanato: o caso do Rio Grande do Norte. Rev. adm. empres., São Paulo, v. 33, n. 1, p. 30-38, fev. 1993. Disponível em: $<$ http://www.scielo.br/scielo.php?script=sci_arttext\&pid=S003475901993000100004\&lng=en\&nrm=iso $>$. Acesso em: 25 ago. 2014.

TOSTA, K. C. B. T. A Universidade como catalisadora da inovação tecnológica baseada em conhecimento. 2012. 239 p. Tese (Doutorado em Engenharia e Gestão do Conhecimento) - Programa de Pós-Graduação em Engenharia e Gestão do Conhecimento, Universidade Federal de Santa Catarina (UFSC), Florianópolis, 2012. Disponível em: $<$ http://btd.egc.ufsc.br/wp-content/uploads/2013/01/KellyCristina-BenettiTonaniTosta.pdf $>$. Acesso em: 28 mar. 2015. 
URDAN, F. T.; URDAN, A. T. Gestão do composto de marketing. 2. ed. São Paulo: Atlas, 2013.

WESTWOOD, J. O plano de marketing. 3. ed. São Paulo: Makron Books, 2007. 